\title{
ESTRUTURAS CONTEMPORÂNEAS DE COMUNICAÇÃO CIENTÍFICA E A ORGANIZAÇÃO INSTITUCIONAL ${ }^{1}$ CONTEMPORARY STRUCTURES OF SCIENTIFIC COMMUNICATION
AND THE INSTITUTIONAL ORGANIZATION
}

\author{
Sueli Mara S.P. Ferreira - smferrei@usp.br \\ Professora Associada e Dra. em Ciências da Comunicação pela ECA/USP \\ Orientadora credenciada no Programa de Pós-Graduação em Ciência da Informação da \\ ECA/USP
}

\begin{abstract}
Resumo
O desenvolvimento das TIC e as atuais formas de poder vigentes no ambiente científico, alteram substancialmente as estruturas contemporâneas da comunicação científica, o encaminhamento do fluxo informacional, as responsabilidades dos stakeholders e, obviamente, o próprio modelo de seu produto fundamental, qual seja o periódico científico. Traçar algumas considerações e questionamentos acerca dos novos papéis que devem ser assumidos (ou reassumidos) pela comunidade científica é o objetivo deste texto, enfocando especialmente as atribuições dos portais institucionais e/ou temáticos de periódicos. Para tanto, este texto recupera o surgimento das revistas científicas e seu papel primordial no seio da comunicação da ciência, buscando evidenciar a forte atuação dos pesquisadores. Aponta, também, a mudança de enfoque com o surgimento dos editores nacionais e internacionais e, logo a seguir, discute nova alteração no que se refere às responsabilidades científicas, com o surgimento dos movimentos internacionais OAI (Open Archives Initiative) e OA (Open Access). Conclui com sugestões sobre o papel dos atuais portais institucionais e/ou temáticos de revistas científicas, evidenciando novos compromissos a serem seguidos pela comunidade.
\end{abstract}

Palavras-chave: Comunicação científica. Portal de revistas científicas. Publicações eletrônicas.

\section{INTRODUÇÃO}

O desenvolvimento das tecnologias de informação e comunicação (TIC), em especial aquelas vinculadas ao ambiente digital, está alterando substancialmente as estruturas contemporâneas da comunicação científica, o encaminhamento do fluxo informacional, as responsabilidades assumidas pelos diversos stakeholders do processo e, obviamente, o próprio modelo de seu produto fundamental, qual seja o periódico científico.

Paralelo a este avanço tecnológico, tem-se também a discussão das atuais estruturas de "poder" no ambiente científico e a reavaliação do papel de cada componente do

\footnotetext{
${ }^{1}$ Palestra proferida na mesa redonda A comunicação científica no Brasil: estratégias de diálogo científico em âmbito internacional durante o II Simpósio Brasileiro de Comunicação Científica, realizado na Universidade Federal de Santa Catarina - UFSC, Florianópolis, nos dias 05 e 06 de maio de 2008. Evento comemorativo ao lançamento do Portal Periódicos UFSC.
}

Enc. Bibli: R. Eletr. Bibliotecon. Ci. Inf., Florianópolis, n. 26, $2^{\circ}$ sem.2008

Dossiê: II Simpósio Brasileiro de Comunicação Científica, p. 1 
processo comunicacional, acelerando o processo de revisão e reformulação das políticas vigentes em ciência e tecnologia, tanto em âmbito internacional como nacional. Cada vez mais se torna atual e real a pergunta já formulada por Meadows (1999) “como é possível atender melhor às atividades de comunicação dos pesquisadores num ambiente tecnológico que passa por rápidas alterações?”.

Traçar algumas considerações e questionamentos acerca dos papéis e responsabilidades que devem ser assumidos (ou retomados) pela comunidade científica brasileira, neste contexto, é o objetivo deste texto, enfocando especialmente possíveis atribuições que os portais institucionais e/ou temáticos de revistas científicas podem assumir no país. Não se trata de consolidar afirmações ou formalizar propostas, mas sim de iniciar reflexões sobre interpretações e possibilidades percebidas. Tais reflexões se justificam exatamente neste momento, quando se dá o surgimento destes portais em diversas instituições de ensino superior e em áreas específicas do conhecimento.

Para tanto, este texto recupera o surgimento das revistas científicas e seu papel primordial no seio da comunicação da ciência, buscando evidenciar a forte atuação dos pesquisadores naquele momento; a seguir aponta a mudança de enfoque e atuação da comunidade com o surgimento dos editores nacionais e internacionais de revistas e, logo a seguir, aponta sua nova mudança de atuação e responsabilidade com o surgimento dos movimentos internacionais OAI (Open Archives Initiative) e OA (Open Access). Conclui com indicação de possíveis papéis a serem assumidos pelos atuais portais institucionais e/ou temáticos de revistas científicas no cenário científico brasileiro, evidenciando novos compromissos a serem seguidos pela comunidade científica.

\section{A COMUNICAÇÃO CIENTÍFICA E O PAPEL DA COMUNIDADE CIENTÍFICA}

As significativas descobertas científicas ocorridas no século XVII apontam-no como o marco inicial da formalização da comunicação científica, em especial devido à criação da Royal Society em Londres e ao surgimento de duas revistas científicas: o Journal de Sçavans e o Philosophical Transactions.

Segundo Weitzel (2005, p. 166),

a criação da Royal Society (Londres), em 1662, pode ser um marco da concepção cartesiana de mundo em oposição à concepção aristotélica e católica, expressando novo paradigma da ciência, no período das revoluções científicas. Trata-se de uma instituição que reúne as condições para institucionalizar os procedimentos seculares visando o estabelecimento de um sistema de comunicação da ciência, segundo os moldes sugeridos nos trabalhos de Francis Bacon”.

Um destes procedimentos utilizados pelos cientistas foi a criação do modelo de revista, o qual perdura até os dias de hoje. Embora elas tenham surgido como um mecanismo, pautado na tecnologia da imprensa, para substituir a troca de idéias e a distribuição geralmente esporádica de folhas noticiosas e cartas manuscritas entre um pequeno círculo de amigos, as revistas logo se transformaram em algo mais formalizado, levando a implicações notáveis para a comunicação científica e ao desenvolvimento da ciência. Sua proposta primária foi, portanto, a troca imediata de informações entre os cientistas, Enc. Bibli: R. Eletr. Bibliotecon. Ci. Inf., Florianópolis, n. 26, $2^{\circ}$ sem.2008 
veiculação ampla de novas idéias, documentação de opiniões e compartilhamento de resultados.

Segundo Meadows (1999), uma das principais mudanças, decorrente do surgimento das revistas, foi a formalização do processo de comunicação científica, antes pautado fortemente na comunicação "informal" (que é efêmera e para públicos limitados). A comunicação formal (disponível por longo período de tempo e para público amplo) impacta sobremaneira o padrão de comportamento da comunidade, sua possibilidade de acesso, a formalização de sua produção e o registro da memória científica.

Porém, tal mudança foi possível e plausível somente por conta da existência das sociedades (ou associações) científicas, isto é, de grupos de pessoas envolvidas na comunicação da ciência (tanto formal como informal), fornecendo informação sobre seu próprio trabalho a outras pessoas e recebendo de informações dessas pessoas, bem como na acumulação deste conhecimento e divulgação de forma durável e prontamente acessível. Neste contexto é que surge a célebre frase de Isaac Newton - se enxerguei mais longe foi porque me apoiei nos ombros de gigantes.

Segundo Meadows (1999, p.9),

"os membros da sociedade relatavam suas próprias pesquisas, organizavam demonstrações ou exposições, mantinham contatos e intercambiavam mexericos profissionais (sempre uma forma importante de consolidar o quadro de sócios). Muitas sociedades estabeleceram paralelamente um programa editorial. Assim, satisfaziam aos anseios dos sócios que almejavam tornar público seu trabalho, permitiam a não-sócios terem acesso aos trabalhos desenvolvidos pela sociedade e proporcionavam um registro que podia ser transmitido às gerações futuras”.

Corrobora com esta idéia Vickery (1999), quando menciona que “durante séculos as sociedades científicas assumiram função vital na institucionalização do modelo científico, uma vez que têm o mérito de promover a educação contínua e mútua entre os pesquisadores, por meio de eventos, reuniões, publicações e criação de bibliotecas”. Ou seja, nos primórdios das revistas a comunidade científica estruturava, definia, implementava e gerenciava todo o processo da comunicação, desde o surgimento da idéia, até seu registro (seguindo normas por ela mesma definida), divulgação, distribuição, uso e reuso por meio de mecanismos de acesso controlados.

Este modelo vai se formalizando e cerca de duzentos anos depois, por volta de 1892, já existiam 470 títulos de periódicos no mundo todo. As revistas científicas, visando dar maior credibilidade ao processo de comunicação, adotam desde seu início, o princípio de validação do mérito e do método científico pela comunidade. Para tanto, surgem regras e normas para a apresentação dos resultados de pesquisa, para a formatação e apresentação deles e, obviamente para sua respectiva avaliação. Quanto a avaliação, tem-se à posição assumida desde os primórdios, referente à revisão pelos pares (processo denominado atualmente como peer review ou sistema de arbitragem) que, segundo Pessanha (1998), surgiu em 1753 quando a Royal Society of London passa a responsabilizar-se formalmente pela avaliação dos textos publicado

Com o passar dos anos, diversas mudanças contextuais, tecnológicas e sociais alteram, exigem e/ou geram adaptações nestas regras e normas, tais como: 
- melhoria no formato das revistas e artigos (por exemplo, nos títulos dos artigos de periódicos tornando-os mais objetivos do que os títulos dos livros, ou o surgimento de autoria e co-autoria e, até mesmo, a introdução do resumo no corpo do artigo);

- surgimento de inúmeras associações (nacionais e internacionais) e em distintas áreas ou subáreas do conhecimento exigindo mais especificidade na produção do conhecimento e surgimento de revistas especializadas;

- desenvolvimento do modelo de pesquisa e de formação de pessoal (formalizam-se as distintas modalidades de formação: graduação, mestrado, doutorado e assim por diante);

- demanda pelas atividades de pesquisas de interesse do público em geral pelos meios de comunicação de massa (especialmente depois da $2^{\mathrm{a}}$. Guerra Mundial), portanto, exigindo maior disseminação e agilidade na divulgação de resultados

- ascensão da língua inglesa ao posto de língua franca científica promovida pelas editoras científicas internacionais (diferentes de editoras nacionais que se empenhavam em conquistar um público internacional para seus autores majoritariamente nacionais);

- e em especial a explosão bibliográfica (década de 1940/50) levando ao surgimento da indústria de informação.

Neste momento, o sistema de comunicação científica vigente é obrigado a se reajustar, buscando novas alternativas para aumentar sua eficiência tanto no que tange ao controle e avaliação, como a distribuição e disseminação do que está sendo produzido. A partir desta época, segundo Weitzel (2005, p.169) “aumenta-se o reconhecimento da relevância do trabalho cientifico (valor epistêmico), da publicação em si como valoração dos que adotam as normas comportamentais de Merton (valor moral). E assim, o sistema de revisão de pares ganha conotação de controle social para atribuição desse reconhecimento como recompensa”. Autores como Le Coadic (2004), também comentam a distorção da função das revistas levando ao surgimento do lema "publique ou pereça”" (década de 60).

Com a indústria de informação, surgem as editoras internacionais que passam a assumir as atividades de edição, publicação e distribuição das revistas científicas produzidas por comunidade científica de diversos países. Este novo modelo de negócios aumenta substancialmente o número de títulos já existente. Conseqüentemente, gera uma necessidade de soluções ágeis e fáceis para melhoria do acesso frente a sobrecarga de informação, e ainda novas formas de valoração das próprias revistas visando estabelecer hierarquia entre elas.

Como resposta ao primeiro problema proliferam os serviços de bibliografia especializada (index ou abstracts como são normalmente conhecidos) e, para o segundo problema, surgem os índices de citação (inicialmente pautado no modelo do Institute for Scientific Information (ISI), hoje ISI/Thompson). Esses novos serviços agregam maior acessibilidade e visibilidade à produção científica e, logo, passam a orientar e fornecer os parâmetros e os indicadores de qualidade vigentes e aceitos pela comunidade

Enc. Bibli: R. Eletr. Bibliotecon. Ci. Inf., Florianópolis, n. 26, $2^{\circ}$ sem.2008

Dossiê: II Simpósio Brasileiro de Comunicação Científica, p. 4 
científica internacional até hoje, especialmente no que tange ao uso do índice de fator de impacto gerado a partir do estudo de citações.

Com todo este aparato, as revistas se consolidam como um dos mais importantes canais de comunicação e divulgação do conhecimento científico e passam a servir de apoio fundamental a avaliação dos critérios de qualidade da área, dos resultados de pesquisas e, conseqüentemente, de quem nelas pubblicam. Esses critérios, subsidiarão, posteriormente, as ascensões profissionais dos membros da comunidade acadêmica, a distribuição de apoios financeiros a grupos de pesquisa, a definição de políticas públicas dentre outros.

Segundo Guédon (no prelo), a revista passa a ofertar diversificados espaços para o exercício do poder: por exemplo editar um periódico influente, participar do comitê editorial ou do corpo de avaliadores (referees)

periódicos científicos passam a ser não somente órgãos de divulgação; eles também servem como plataformas de mediação. Cientistas que desempenham uma função nesses periódicos influenciam as maneiras pelas quais são selecionados os manuscritos apresentados. Eles também aumentam sua visibilidade e status graças ao trabalho que fazem: o simples despacho de artigos para examinadores implica a presença de uma forte rede que está sendo regularmente alimentada e reforçada por contatos sistematicamente renovados. Concorrer por um cargo editorial faz parte da concorrência no campo científico.

Estabelece-se, assim, um sistema de qualificação e controle da ciência que passa a abranger tanto critérios nacionais como internacionais

... o desenvolvimento de um sistema internacional de concorrência científica levou o campo científico a evoluir gradualmente para um sistema de dois níveis, sendo um nacional e o outro internacional. O nível internacional passou a atuar como o principal árbitro da qualidade, enquanto o nível nacional inclui misturas mais complexas de avaliação de qualidade com política institucional e, às vezes, a política pura e simples (GUÉDON, no prelo).

O sistema internacional que emerge implementa uma reformulação da comunicação científica, agregando-lhe novos atores, reajustando e redistribuindo funções e atividades que acabam por impactar a política científica nacional de diversos países. A partir deste modelo, as grandes editoras internacionais assumem a responsabilidade da edição, publicação, distribuição, divulgação e disseminação dos resultados de pesquisas produzidas em diversos países. Além de deter os direitos autorais do autor, as editoras se vêem às voltas de definir quais são as principais revistas e, conseqüentemente, de estabelecer seu valor financeiro. Portanto, impactando a comunidade acadêmica que deverá adquirir tais revistas para ter o devido acesso aos resultados de pesquisas ali publicados.

Por outro lado, a editora assume a responsabilidade de garantir as melhores posições no mercado para suas revistas, providenciar sua inserção nos mecanismos mais qualificados de indexação e índice de citação e atuar no aumento do fator de impacto da

Enc. Bibli: R. Eletr. Bibliotecon. Ci. Inf., Florianópolis, n. 26, $2^{\circ}$ sem.2008

Dossiê: II Simpósio Brasileiro de Comunicação Científica, p. 5 
revista, constantemente, por meio de uma bem planejada campanha de promoção, divulgação e venda de assinaturas.

A inserção de resultados em revistas internacionais, que façam parte do "core" identificado, é cada vez mais valorizada e incentivada nas políticas nacionais. Tal situação acaba por "engessar" o crescimento de revistas fora do padrão definido, em especial para as revistas de países em desenvolvimento, as quais dificilmente estarão no idioma e segundo as qualidades exigidas, inclusive no que se refere as temáticas desenvolvidas, a presença de autores estrangeiros e pontualidade na publicação

Neste ambiente, percebe-se uma situação complexa onde o papel e a responsabilidade da comunidade científica parecem ficar limitados à pesquisa, produção e avaliação de resultados, ausentando-se do poder de decisão quanto às melhores formas de uso e divulgação destes mesmos resultados.

Portanto, este modelo acaba por suscitar uma crise séria, atribuída a diversos fatores, dentre eles:

- dificuldades financeiras - referente ao alto custo de assinaturas imposto pelas editoras inviabilizando a aquisição pelas bibliotecas universitárias,

- problemas éticos - decorrentes da pressão para se publicar em revistas que façam parte do núcleo básico ocasionando falta de transparência no processo de avaliação e a mudança de foco da revista que passa a ser mais útil para autopromoção do que por desenvolver a ciência e, ainda,

- concentração de direitos autorais nas mãos do setor privado - uma vez que a cessão deles às editoras inviabiliza a divulgação da produção nacional em seus países de origem, por exemplo.

Todos esses problemas citados, acabam por diminuir a visibilidade e acessibilidade aos resultados de pesquisas. O surgimento da internet, da web e de suas tecnologias derivadas vem oferecer, aos pesquisadores descontentes com esse modelo, o ambiente necessário para a construção de propostas alternativas. Surgem assim dois movimentos internacionais: a Open Archives Initiative (Iniciativa dos Arquivos Abertos, doravante intitulado $\mathrm{OAI}^{2}$ ) e o Open Access (Movimento do Acesso Aberto, doravante intitulado $\left.\mathrm{OA}^{3}\right)$.

\section{MOVIMENTOS OAI E AO E A TRANSFORMAÇÃO DA COMUNICAÇÃO CIENTÍFICA}

Segundo Ferreira (2007) esses dois relevantes movimentos - a Iniciativa dos Arquivos Abertos (OAI) e o Movimento do Acesso Aberto (OA) representam um marco na história da comunicação científica, pois oferecem respectivamente:

\footnotetext{
${ }^{2}$ Maiores informações ver URL: http:// www.openarchives.org/

${ }^{3}$ Ainda não parece haver consenso na discussão entre pesquisadores brasileiros sobre a melhor tradução para Open Access, alguns utilizam a expressão Acesso Aberto e outros utilizam Acesso Livre. Optou-se aqui por utilizar a primeira opção, adotando-se aqui a proposta de Bailey (2005) de que o termo "aberto" se refere a opção de uso do conteúdo respeitando-se os direitos autorais dos envolvidos, enquanto "livre" se refere ao modelo de negócio da revista gratuita. Mais informações sobre tal movimento ver - URL: http://www.ibict.br/openaccess.
}

Enc. Bibli: R. Eletr. Bibliotecon. Ci. Inf., Florianópolis, n. 26, $2^{\circ}$ sem.2008

Dossiê: II Simpósio Brasileiro de Comunicação Científica, p. 6 
- soluções técnicas efetivas, ágeis, econômicas e viáveis para que comunidades científicas reconstruam práticas e processos de comunicação científica, sistemas de gestão cooperativos, mecanismos de controle bibliográfico, preservação da memória, promovendo assim a consolidação de seu corpus de conhecimento.

- suporte teórico e respaldo político que possibilitam e suportam a discussão sobre a disseminação ampla e irrestrita do conhecimento (principalmente aquele gerado com financiamento público); a legitimação e institucionalização de novos sistemas de publicação científica, a revisão das práticas associadas à concessão de seus direitos de autor aos editores comerciais, a transparência necessária no processo de peer-review e o compartilhamento público sem custos, dentre outras questões. (Ferreira, 2007, p. 142).

O movimento OAI surgiu em 1999, liderado por um grupo de pesquisadores europeus e norte-americanos, com o propósito específico de repensar o processo de comunicação científica eletrônica. Trata-se de uma iniciativa para desenvolver e promover padrões e normas de interoperabilidade para facilitar a eficiente disseminação de conteúdos na Internet. O termo arquivo (archives) é entendido em sentido amplo como espaço controlado para o armazenamento de informações digitais, enquanto o termo aberto (open) se refere à arquitetura do sistema ${ }^{4}$, interfaces que facilitem a disponibilidade de conteúdos procedentes de uma variedade de sistemas.

O movimento OA inicia-se em 2003 quando pesquisadores internacionais se reúnem para discutir as dificuldades encontradas pela comunidade mundial no acesso à informação científica, dando origem à discussão e elaboração de diversos manifestos internacionais conhecidos como Declarações de Budapeste (dez./2001) ${ }^{5}$, de Bethesda (abr./2003) ${ }^{6}$, de Berlim (out./2003) ${ }^{7}$, do Minho (nov.2006) ${ }^{8}$ além de manifestações de organizações internacionais não governamentais como a Federação Internacional de Associações de Bibliotecas (IFLA), Organização para a Cooperação e o Desenvolvimento Econômico (OCDE) e outras.

Trata-se de uma rediscussão sobre o papel fundamental da comunicação científica no que se refere ao papel social da ciência e da pesquisa, pleiteando portanto, formas para se disponibilizar à sociedade o acesso aberto $^{9}$ aos resultados de todas as pesquisas desenvolvidas internacional e nacionalmente (em especial aquelas financiadas com dinheiro público). Trata-se, portanto, de uma estratégia que tem forte potencial e

\footnotetext{
${ }^{4}$ Software open source - possuem seus códigos fontes abertos facilitando a implementação de alterações e adaptações de acordo com as necessidades e especificidades dos usuários.

${ }^{5}$ Declaração de Bethesda - URL://http://www.soros.org/openaccess/read.shtml

${ }^{6}$ Budapest Open Access Initiative/BOAI - URL: http://

http://www.earlham.edu/ peters/fos/bethesda.htm

${ }^{7}$ Declaração de Berlim - URL: http://www.inist.fr/openaccess/article.php3?id_article=38

${ }^{8}$ URL ver URL: http://www.ibict.br/openaccess/

${ }^{9}$ Por "acesso aberto" entende-se a livre publicação na Internet de literatura de caráter acadêmico ou científico (em particular os artigos de revistas científicas), permitindo a qualquer cidadão ler, baixar, copiar, distribuir, imprimir, pesquisar ou referenciar ("linkar") o texto na íntegra (Bethesda, 2003).
}

Enc. Bibli: R. Eletr. Bibliotecon. Ci. Inf., Florianópolis, n. 26, 2º sem.2008

Dossiê: II Simpósio Brasileiro de Comunicação Científica, p. 7 
sustentação para a reformulação das políticas nacionais, principalmente nos países em desenvolvimento.

Esses dois grandes movimentos internacionais se complementam na elaboração, desenvolvimento e implementação de políticas, estratégias, normas, regras e produtos tecnológicos que suportem todas as necessidades e expectativas da comunidade científica internacional no que se refere à produção científica. Inclui-se aqui, obviamente, a discussão da detenção dos direitos do autor de disseminar seus resultados de maneira diferenciada da situação vigente, bem como o acesso aberto e público aos resultados de pesquisas especialmente financiadas com recursos públicos.

Ambos movimentos, portanto, podem e devem ser visualizados como uma retomada de posicionamento da própria comunidade acadêmica frente ao seu papel no contexto da comunicação científica. As propostas surgidas no âmago do OAI e do OA proporcionam e exigem uma revisão do fluxo da produção científica e uma redefinição dos papéis assumidos por todos os atores (stakeholders) envolvidos na cadeia de comunicação: pesquisadores, editores, editoras, bibliotecas, instituições de ensino superior, agências de fomento e governamentais. Além disto, reforçam e possibilitam também uma revisão dos critérios de avaliação utilizados e derivados do modelo existente de avaliação com base em revistas e no fator de impacto das mesmas, tendo em vista sua interpretação à luz da realidade e ambiência de distintas áreas do conhecimento.

Conforme já mencionado por Meadows (1999, p.vii), durante seus estudos com pesquisadores de áreas de astronomia, história da ciência, biblioteconomia e estudos de informação:

Os pesquisadores destas áreas vêem o mundo de ângulos distintos; suas idéias divergem quanto à natureza do que seja conhecimento aceitável, e as respectivas comunidades de pesquisa se organizam de modo diverso. Por isso, diverge o modo como lidam com a informação. As mudanças que afetam o mundo científico, em sua totalidade, não causam necessariamente impactos idênticos na comunicação das pesquisas em ciências e humanidades.

Dizer que as áreas se organizam de modo diverso implica uma série de situações, dentre elas a observação de que a valoração e supremacia das revistas é possível no ambiente da ciência mas não necessariamente nas humanidades (onde elementos como livros, eventos, catálogos etc. também devem entrar no circuito de avaliação) e ainda que estudos bibliométricos (base para a análise de fator de impacto) são imprescindíveis, mas devem ser tratados com moderação, tendo em vista que o processo de citação também varia enormemente da ciência para a humanidade e que avaliações quantitativas não podem ser consideradas isoladamente.

\section{O REFLEXO DESTES MOVIMENTOS NO BRASIL}

No Brasil, como na maioria dos países, a avaliação da ciência se dá nos moldes citados anteriormente: pesquisadores e universidades são avaliados e supervalorizados a partir da publicação em revistas científicas indexadas em bases bibliográficas internacionais e com alto fator de impacto. Vale lembrar que esta métrica foi criada e proporcionada, por décadas, pelo Journal Citation Index da ISI/Thompson disponível no Web of Science, o

Enc. Bibli: R. Eletr. Bibliotecon. Ci. Inf., Florianópolis, n. 26, 2º sem.2008

Dossiê: II Simpósio Brasileiro de Comunicação Científica, p. 8 
qual privilegia revistas americanas e que, até 4 anos atrás, somente incluía revistas publicadas em inglês e seguindo rigorosos critérios de qualidade (como conteúdo de pesquisa de interesse internacional e pontualidade na publicação dos fascículos, por exemplo).

Portanto, a publicação em revistas estrangeiras sempre representou busca constante por imensa parcela de pesquisadores brasileiros, tendo em vista que pouquíssimas revistas brasileiras são indexadas por algum serviço de bibliografia corrente e menos ainda possuem fator de impacto. Exceto a área de saúde que conta com a infraestrutura da BIREME (Centro Latino Americano e do Caribe de Informação em Saúde), as demais áreas carecem de serviços apropriados e profissionais para indexação de sua produção científica.

Assim, durante décadas a pesquisa produzida no Brasil (o mesmo ocorrendo nos demais países latino-americanos) viveu uma situação de grande desamparo, devido ao modelo aceito e valorizado pelas próprias instituições de ensino superior, agências de fomento e governo local.

Com a evolução tecnológica e o surgimento dos movimentos internacionais (OAI e OA) mencionados, algumas alterações começam a ser observada no país. Pode-se afirmar que o início destas alterações, foi a proposta desenvolvida pela equipe da BIREME em parceria com a FAPESP (Fundação de Apoio a Pesquisa do Estado de São Paulo) e a OPAS (Organização Pan-Americana de Saúde) que iniciou o desenvolvimento de uma metodologia para valorizar a produção científica produzida nestas regiões, tendo como base o modelo vigente, ou seja, o processo de citação.

Nasce assim, em 1999, o projeto SciELO (Scientific Eletronic Library Online) com a proposta de publicar eletronicamente os periódicos de saúde parceiros de sua rede, indexar suas citações, gerar os fatores de impacto e criar a rede científica e social existente entre as revistas e os respectivos pesquisadores brasileiros parceiros. Logo se segue a inserção de revistas de outras áreas além da saúde, mas sempre observando critérios de qualidade semelhantes aos utilizados em serviços bibliográficos internacionais. Finalmente, o projeto assume visibilidade internacional, com a implementação de Portais em diversos países da América Latina, Caribe, Europa e, atualmente encontra-se em estudos sua adoção na África do Sul ${ }^{10}$. Em setembro de 2008, o Projeto SciELO conta com 554 títulos de revistas em todo o mundo, sendo aproximadamente 217 títulos brasileiros.

O modelo SciELO se encontra alinhado aos movimentos internacionais mencionados, ao OAI no sentido de que utiliza o protocolo OAI/PMH permitindo coleta ampla por provedores de serviços e, ao OA pois disponibiliza seu conteúdo para acesso público e gratuito, seguindo a "rota dourada” proposta por Steven Harnard (Harnard et al., 2004).

Esta rota somada à rota verde, prescrevem os modelos de atuação para as revistas e respectivos editores propostos pelo OA, a saber:

- a rota dourada (Gold Road) - se refere à proposta de que a implementação de revistas seja totalmente em formato aberto e interoperável, com acesso público garantido pelos editores; já a

\footnotetext{
${ }^{10}$ URL: http://blogs.uct.ac.za/blog/gray area/2008/08/05/assaf-visits-scielo

Enc. Bibli: R. Eletr. Bibliotecon. Ci. Inf., Florianópolis, n. 26, $2^{\circ}$ sem.2008

Dossiê: II Simpósio Brasileiro de Comunicação Científica, p. 9
} 
- rota verde (Green Road) se refere à opção vinculada ao auto-arquivamento, ou seja, os editores das revistas aceitam que os autores possam depositar livremente UMA CÓPIA de seus trabalhos em algum repositório público de acesso aberto.

No Brasil, têm-se as "duas rotas" sendo implementadas. A primeira, rota dourada, como já foi dito, com forte atuação do Projeto SciELO, mas também com outra importante iniciativa - o Programa SEER (Sistema de Editoração Eletrônica de Revistas) proposto pelo IBICT (Instituto Brasileiro de Informação em Ciência e Tecnologia). Trata-se de um programa para apoiar e aumentar a inserção das revistas nacionais no mundo digital e no modelo dourado, tendo como foco a promoção de revistas de acesso aberto e a capacitação da comunidade científica no que se refere à melhoria da qualidade de suas revistas. Para tanto, o IBICT customizou o software OJS (Open Journal System) da British Columbia University no Canadá, oferecendo suporte técnico e capacitação de pessoal. Em setembro de 2008, 450 revistas brasileiras já estão registradas e utilizando tal modelo.

Já quanto à rota verde, o Brasil também se encontra bastante avançado. Simultaneamete, está em tramitação o Projeto de Lei PL 1120, proposto pelo Deputado Federal Rodrigo Rollemberg à Camâra dos Deputados. Aprovado em primeira instância, este projeto traz as seguintes propostas:

- é aconselhável que todas as IES, de caráter público, assim como as unidades de pesquisa, construam seus repositórios institucionais, para depositar toda a produção técnico-científica de seus corpos docente, discente e de pesquisadores.

- tal conteúdo deverá ser disseminado via a rede mundial de computadores, Internet, de forma aberta.

- deve ser criada uma Comissão para definir Política Nacional de Acesso Aberto à Informação Científica.

Caso este projeto de lei seja aprovado, o país será o primeiro do mundo a ter legislação própria e específica para o acesso aberto.

No que se refere as estratégias tecnológicas, o IBICT já customizou e disponibilizou gratuitamente para a comunidade vários softwares específicos para implementação de repositórios digitais (por exemplo, o Dspace do MIT e HP), de repositórios temáticos (por exemplo, o Eprints da Southampton University) ou repositórios focados em fontes de informações (por exemplo, o OCS/SOAC desenvolvido pela British University do Canadá para anais eletrônicos e o TEDE para teses e dissertações desenvolvido pelo próprio IBICT).

Do ponto de vista técnico, várias ações de treinamento, capacitação, produção de material didático e mesmo uma ação junto aos reitores de diversas universidades brasileiras têm sido feitas para incentivar e fomentar o desenvolvimento de repositórios digitais para o auto-arquivamento.

Com todo este suporte, o Brasil é um dos países com potencial para se tornar vanguarda em relação ao tema do acesso aberto. Deste modo, sem sombra de dúvida, podemos dizer que este país está caminhando a passos de gigante para a consolidação da melhor e mais apropriada disseminação e consolidação da ciência aqui produzida.

Com base nestas iniciativas acima mencionadas, as agências governamentais e de fomento brasileiras (como em outros países) já adotaram formalmente os periódicos de

Enc. Bibli: R. Eletr. Bibliotecon. Ci. Inf., Florianópolis, n. 26, 2º sem.2008

Dossiê: II Simpósio Brasileiro de Comunicação Científica, p. 10 
acesso aberto, inclusive incentivando sobremaneira sua implementação. A CAPES incentiva os editores explicitamente a utilizar o padrão SciELO, o Seer/OJS, ou ambos em suas publicações. $\mathrm{O} C N P q$, atuando via IBICT, disponibiliza gratuitamente o software OJS/SEER e todo o suporte já comentado anteriormente. E a FAPESP, via SciELO, inicia também um processo de abertura de sua tecnologia para as comunidades que queiram criar seus portais específicos.

Inicia-se assim uma reação nas atividades das revistas científicas, uma busca do suporte da publicação eletrônica para garantir sua inserção no ambiente digital, além de uma revitalização no processo da comunicação científica, principalmente envolvendo as próprias instituições, as bibliotecas, os pesquisadores e até as agências de fomento. É neste momento que surgem os portais institucionais e/ou temáticos de revistas científicas, objeto de discussão desta reflexão.

\section{PORTAIS INSTITUCIONAIS E/OU TEMÁTICOS DE REVISTAS CIENTÍFICAS}

Conforme já mencionado, os papéis desempenhados pelo IBICT e da BIREME têm sido fundamentais no que se refere ao desenvolvimento de tecnologias, treinamento de pessoal e, mais importante, no esclarecimento da comunidade científica brasileira quanto ao modelo atual de comunicação científica, seguido de motivação para a segura inserção da comunidade de pesquisadores, editores, instituições de ensino superior, bibliotecas e sociedade nesse modelo.

Como conseqüência, a própria comunidade científica brasileira inicia seu envolvimento nas atuais questões da comunicação científica reassumindo alguns dos processos esquecidos: a disseminação, a visibilidade e a acessibilidade da produção científica, buscando gerar mecanismos que garantam, preservem e melhorem sua visibilidade, uso e responsabilidade social.

Neste contexto, surgem os portais temáticos - ou seja portais contendo revistas científicas de áreas específicas do conhecimento, e os portais institucionais - portais contendo revistas científicas publicadas por uma dada instituição.

Tais portais podem estar utilizando a metodologia da SciELO ${ }^{11}$, como por exemplo: Periódicos Eletrônicos de Psicologia ${ }^{12}$, Portal de Revistas de Enfermagem ${ }^{13}$, Portal de Revistas de Odontologia (em construção) ou o Portal de Revistas da Universidade de São Paulo (em construção).

Outros portais estão recorrendo ao software OJS/SEER, como por exemplo: Portal Univerciência - Revistas Eletrônicas de Ciências da Comunicação ${ }^{14}$, Portal de Revistas

\footnotetext{
11 A BIREME mantém o Portal Scielo que busca garantir a qualidade das publicações brasileiras. Porém, visando contribuir para o desenvolvimento e melhoria das demais revistas nacionais (de modo que elas possam vir a fazer parte da coleção SciELO em futuro próximo) e também com as instituições de ensino superior no que se refere a manutenção e gerenciamento de sua própria coleção, a BIREME vêm abrindo concessão especial de uso do seu software para implementação de coleções específicas.

12 http://pepsic.bvs-psi.org.br/scielo.php

13 http://www.portalbvsenf.eerp.usp.br/scielo.php

${ }^{14}$ http://www.revistas.univerciencia.org
}

Enc. Bibli: R. Eletr. Bibliotecon. Ci. Inf., Florianópolis, n. 26, 2º sem.2008

Dossiê: II Simpósio Brasileiro de Comunicação Científica, p. 11 
da Universidade Federal de Santa Catarina ${ }^{15}$, Portal de Revistas da Universidade Estadual de Maringá ${ }^{16}$, Portal da Universidade Federal do Paraná ${ }^{17}$, dentre outros.

No que se refere as revistas, elas podem (e devem) estar presentes em mais de um portal, ou seja, no institucional e também em algum temático ou mesmo no Portal SciELO. Extrapolando o território nacional, tais revistas também poderão vir a estar incluída em portais regionais e/ou internacionais, dependendo novamente das políticas e do trabalho de qualificação e controle a ser desenvolvido pelos respectivos editores. Isto porque ambas as tecnologias mencionadas foram desenvolvidas seguindo os padrões internacionais de interoperabilidade.

Portanto, neste momento já se vislumbra a necessidade de uma definição de políticas institucionais, focadas no ambiente eletrônico, resguardando-se as especificidades e disponibilidade das diversas áreas que cobre. Da mesma forma, uma redefinição de responsabilidades e compromisso junto à manutenção das revistas deverá envolver uma equipe bastante heterogênea e multidisciplinar.

Os editores científicos não podem mais atuar isoladamente ou mesmo sozinho, ele precisa do suporte da editora universitária para a atuação coesa com as políticas institucionais, nacionais e internacionais. Também precisa da equipe da biblioteca para a garantia de sua inserção nos mecanismos nacionais e internacionais de indexação, garantia de maior visibilidade e da melhor recuperação de seus dados. Também exigem uma atuação próxima e personalizada da equipe de informática, para a manutenção, o gerenciamento, o desenvolvimento de plug-in e a atualização constante do software e preocupações com a preservação digital.

A própria comunidade de autores (pesquisadores, docentes e alunos de pós-graduação) deve estar consciente de sua nova responsabilidade, de seus direitos e de seu posicionamento no ambiente científico. A ética no trabalho de revisão, citação, redação e divulgação do conteúdo científico são questões vitais a serem reformuladas.

A redefinição das redes científicas brasileiras temáticas também passa por todas essas preocupações e alterações anteriormente mencionadas. Porém, agravadas um pouco mais, dado que elas deverão refletir uma nação, um grupo de pesquisadores cobrindo distintas subáreas, advindos de diversas instituições (portanto, com várias políticas e regras) e distintas fases de desenvolvimento. Neste momento, o fortalecimento das áreas enquanto grupo consolidado de pesquisa, deverá ser o respaldo necessário para garantir a implementação, o desenvolvimento e a manutenção dos portais temáticos.

\section{$6 \quad$ Finalizando}

Embora bastante recente, o surgimento dos portais temáticos e institucionais de revistas científicas no país já aponta para uma revolução sem retorno dos processos de comunicação científica. Trata-se de uma nova etapa, de um novo fazer científico

\footnotetext{
${ }^{15}$ http://www.periodicos.ufsc.br/

16 http://www.periodicos.uem.br/

17 http://www.prppg.ufpr.br/stricto_sensu/periodicos.html
}

Enc. Bibli: R. Eletr. Bibliotecon. Ci. Inf., Florianópolis, n. 26, $2^{\circ}$ sem.2008 
envolvendo todos os atores do processo e exigindo reformulação das práticas e definições políticas vigentes até então.

Iniciar um Portal de Revistas Eletrônicas não é tarefa elementar e de tempo limitado. Mas sim, de um esforço coletivo, de um trabalho de equipes trans e interdisciplinares com responsabilidades e conhecimentos distintos e em um ambiente novo que exige atualização tecnológica constante; equipe coerente e capacitada; preocupação com aspectos diversos; políticas diversas desde as questões de direitos autorais, normalização e formato de conteúdo, mecanismos de disseminação e regras de acesso e uso do conteúdo; avaliação sistemática tanto do conteúdo como de seu uso pela comunidade; controle da qualidade constantemente visando indexação nacional e internacional; mecanismos apropriados para controle bibliográfico, dentre outros.

A comunidade científica vinculada às instituições de ensino, assim como as distintas áreas e disciplinas têm agora a oportunidade de reformular seus conceitos, reconstruir suas práticas, determinar suas especificidades e definir quais padrões lhe são próprios, qual é seu diferencial, o que deve ser respeitado e como quer ser avaliada. Além disto, reforçam e possibilitam também uma revisão dos critérios de avaliação utilizados e derivados do modelo existente de avaliação com base em revistas e no fator de impacto das mesmas, tendo em vista sua interpretação à luz da realidade e ambiência de distintas áreas do conhecimento.

As propostas surgidas no âmago do OAI e do OA proporcionam e exigem a revisão do fluxo da produção científica e uma redefinição dos papéis assumidos por todos os atores (stakeholders) envolvidos na cadeia de comunicação: pesquisadores, editores, editoras, bibliotecas, instituições de ensino superior, agências de fomento e governamentais. Certamente a construção e consolidação de portais nas diversas instituições e áreas do conhecimento, poderão propiciar em futuro próximo um modelo brasileiro legitimado e institucionalizado a partir da experiência e iniciativa da própria comunidade.

\section{REFERÊNCIAS}

BAILEY JR, C.W. Institutional repositores, tout de suite. 2008. Disponível em: http://www.digital-scholarship.org/ts/irtoutsuite.pdf

BERLIM Declaration on open access to knowledge in the Sciences ahd Humanities. Berlin, 2003. Disponível em: http://oa.mpg.de/openaccessberlin/berlindeclaration.html. Acesso em: 12 novembro 2007.

BETHESDA Statement on Open Access Publishing. Released June 20, 2003. Disponível em: http://www.earlham.edu/ peters/fos/bethesda.htm . Acesso em: 12 novembro 2007.

BOAI - BUDAPEST Open Access Initiative. February, 14th 2002. Available at: http://www.soros.org/openaccess/read.shtml Acesso em: 12 novembro 2007

FERREIRA, S.M.S.P. Fontes de informação em tempos de acesso livre/aberto. In: GIANNASI-KAIMEN, M.J.; CARELLI, A.E. (Orgs) Recursos informacionais para 
compartilhamento da informação: redesenhando acesso, disponibilidade e uso. Rio de Janeiro: E-papers, 2007. p.141 -173.

GUÉDON, J.C. Acesso aberto e a divisão entre ciência "predominante" e "periférica" (Open Access and the divide between "mainstream" and "peripheral" science). In: FERREIRA, S.M.S.P.; TARGINO, M.G. (Orgs). Visibilidade e acessibilidade de revistas científicas. (no prelo). English version available at: http://eprints.rclis.org/archive/00012156/.

HARNARD, S. et alii. The green and gold roads to open access. Nature Web Focus, 2004. Available: http://www.nature.com/nature/focus/accessdebate/ [Accessed May 23, 2005).

KLING, Rob. The internet and unrefereed scholarly publishing. In: CRONIN, Blaise (Ed.). Annual Review of Information Science and Technology, Medford, NJ, v. 38, p. 591-631, 2004.

MEADOWS, A.J. A comunicação científica. Brasília: Briquet de Lemos, 1999.

PESSANHA, C. Critérios editoriais de avaliação científica: notas para discussão. Ciência da Informação, Brasília, v. 27, n. 2, p. 226-229, maio/ago. 1998.

VICKERY, B.A. A century of scientific and technocal information. Journal of Documentation, Londres, v.55, n.5, p.476-527, Dec. 1999

WEITZEL, S.R. E-prints: modelo da comunicação científica em transição. In: FERREIRA, S.M.S.P., TARGINO, M.G. Preparação de revistas científicas: teoria e prática. São Paulo: Reichman, 2005. p.161-194.

\begin{abstract}
The development of the ICT's and the current power structures in the scholarly enviroment are changing, substantially, the structure of contemporary scientific communication, the information workflow, the responsibilities of the stakeholders involved and, of course, the model of your major product - the scientific journal. The objective of this paper is to draw a few comments and questions about new roles that should be assumed by the scientific community, particularly focusing on the tasks of scientific journals portals that has been developed in few areas of knowlodge and also in some universities. In this context, the paper retrieves the scientific journals history and their vital role in the communication of the science, trying to make evident the strong performance of the researchers at that time. After, talk about the change in focus with the development of the national and international publishers. Finally, explore the challenges with all the new responsibilities of the scientific community, specially because of the two international movements: OAI (Open Archives Initiative) and OA (Open Access ). It concludes with suggestions on the role of the scientific journals portals developed by universities or researcher associations in specific field, showing new commitments to be followed by the academic community.
\end{abstract}

KEYWORDS: Scientific Communication. Scientific journals portals. Electronic publications. 